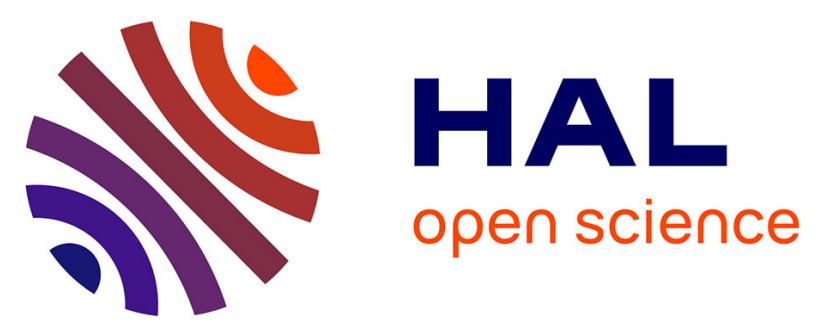

\title{
Transcriptome pathways in leaf and root of grapevine genotypes with contrasting drought tolerance
}

Massimiliano Corso, Alessandro Vannozzi, Elie Maza, Nicola Vitulo, Franco

Meggio, Mondher Bouzayen, Giorgio Valle, Claudio Bonghi, Margherita Lucchin

\section{To cite this version:}

Massimiliano Corso, Alessandro Vannozzi, Elie Maza, Nicola Vitulo, Franco Meggio, et al.. Transcriptome pathways in leaf and root of grapevine genotypes with contrasting drought tolerance. Acta Horticulturae, 2016, 1136, pp.161-168. 10.17660/ActaHortic.2016.1136.22 · hal-01494004

\section{HAL Id: hal-01494004 https://hal.science/hal-01494004}

Submitted on 22 Mar 2017

HAL is a multi-disciplinary open access archive for the deposit and dissemination of scientific research documents, whether they are published or not. The documents may come from teaching and research institutions in France or abroad, or from public or private research centers.
L'archive ouverte pluridisciplinaire $\mathbf{H A L}$, est destinée au dépôt et à la diffusion de documents scientifiques de niveau recherche, publiés ou non, émanant des établissements d'enseignement et de recherche français ou étrangers, des laboratoires publics ou privés. 


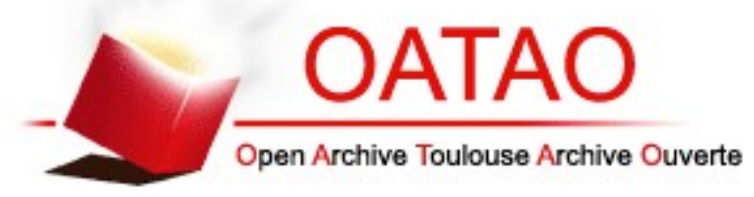

\section{Open Archive TOULOUSE Archive Ouverte (OATAO)}

OATAO is an open access repository that collects the work of Toulouse researchers and makes it freely available over the web where possible.

This is an author-deposited version published in : http://oatao.univ-toulouse.fr/ Eprints ID : 17583

To link to this article : DOI : 10.17660/ActaHortic.2016.1136.22 URL : http://dx.doi.org/10.17660/ActaHortic.2016.1136.22

To cite this version : Corso, Massimiliano and Vannozzi, Alessandro and Maza, Elie and Vitulo, Nicola and Meggio, Franco and Bouzayen, Mondher and Valle, Giorgio and Bonghi, Claudio and Lucchin, Margherita Transcriptome pathways in leaf and root of grapevine genotypes with contrasting drought tolerance. (2016) Acta Horticulturae ( $\left.n^{\circ} 1136\right)$. pp. 161168. ISSN 0567-7572

Any correspondence concerning this service should be sent to the repository administrator: staff-oatao@listes-diff.inp-toulouse.fr 


\title{
Transcriptome pathways in leaf and root of grapevine genotypes with contrasting drought tolerance
}

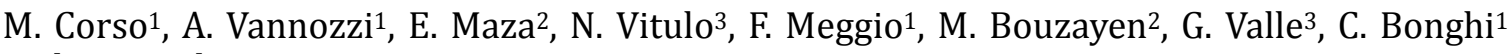 \\ and M. Lucchin ${ }^{1}$ \\ 1Department of Agronomy, Food, Natural Resources, Animals and Environment, DAFNAE, University of Padova, \\ Agripolis - Legnaro, Padova, Italy; ${ }^{2}$ Genomics and Biotechnology of Fruit (GBF) Laboratory, Institut National \\ Polytechnique de Toulouse, Avenue de l'Agrobiopole, F-31326 Castanet-Tolosan Cedex (Toulouse), France; ${ }^{3} \mathrm{CRIBI}$, \\ University of Padova, viale G. Colombo 3, 35121 Padova, Italy.
}

\begin{abstract}
Most of the world's wine-producing regions are subjected to seasonal drought, and, in the light of the dramatic climate-change events occurring in recent years, the selection of resistant rootstocks is becoming a crucial factor for the development of sustainable agricultural models to ensure optimal grape berry development and ripening. In this study, roots and leaves of 101.14 (drought-susceptible) and M4 (drought-tolerant) rootstocks were sampled in progressive drought and mRNA-seq profiles were evaluated. Physiological characterization indicated that only M4 was able to maintain high leaf transpiration and net assimilation rates under severe stress conditions. Statistical analyses, carried out on mRNA-seq data, highlighted that "treatment" (water stress) and "genotype" (rootstock-genotype) seem to be the main variables explaining differential gene expression in roots and leaves tissues, respectively. Upon water-stress, roots and leaves of the tolerant genotype M4 exhibit a higher induction of stilbenes (i.e., STS) and flavonoids (e.g., CHS, F3H, FLS) biosynthetic genes. Moreover, the higher expression of STS genes in M4 is coupled with an up-regulation of WRKYs transcription factors. STS genes promoter regions, extracted from whole genome of M4 and 101.14, highlighted a higher number of $W$ BOX cis elements (binding site for WRKYs) in the tolerant genotype.
\end{abstract}

Keywords: Vitis, water stress, mRNA-seq, flavonoids, stilbenes, WRKY

\section{INTRODUCTION}

Most wine-producing regions in the world are subjected to seasonal drought, and, based on the global climate models predicting an increase in aridity in the future (IPCC, 2007), water deficit may became the major limiting factor in wine production and quality. Drought is associated with many morphological and physiological changes in plants, including reduced expansion of aerial organs (Cramer et al., 2007), lack of root growth (Sharp and Davies, 1979), decrease in transpiration rate and photosynthesis (Chaves et al., 2010), accumulation of osmolytes (Cramer et al., 2007), activation of detoxifying processes. Moreover, it affected the transcriptional regulation of a large number of genes (Cramer et al., 2007; Tillett et al., 2011). Grapevines are well adapted to semi-arid climates such as that of Mediterranean regions and are generally considered as relatively tolerant to water deficit. However, given that a large proportion of vineyards are located in regions where seasonal drought coincides with the grapevine growing season, the combined effect of soil water deficit, air temperature and high evaporative demand is known to limits yield and delays the vintage date (Chaves et al., 2010), with a negative effect on the berries and, consequently, wine quality.

In addition to their well known resistance to phylloxera, rootstocks derived from grapevine American species are known to confer tolerance to a larger range of environmental stresses, such as drought, high salinity and low Fe (Corso and Bonghi, 2014).

A biochemical and physiological study of a novel candidate genotype to be used as rootstock in grapevine was performed recently (Meggio et al., 2014). This genotype, named M4, was selected for its high tolerance to water deficit (WS). In comparison with the 101.14 
commercial genotype, M4 ungrafted plants showed a greater capacity to tolerate WS, maintaining photosynthetic activity also under severe stress conditions. Here we report large-scale whole transcriptome analyses performed on leaf and root tissues of both M4 and 101.14 genotypes under the same WS experimental conditions described by Meggio et al. (2014). Water deprivation in our experiment was accomplished gradually, mimicking conditions occurring in the field. Another innovative aspect of the study is the comparative approach between a drought tolerant and susceptible genotype with regard to water stress, which has not so far been explored.

\section{MATERIALS AND METHODS}

Two-year-old glasshouse-grown plants of the susceptible and tolerant grapevine rootstocks, respectively the widely used 101.14 genotype (V. riparia $\times V$. rupestris $)$ and the experimental M4 ( $V$. vinifera $\times V$. berlandieri $) \times V$. berlandieri 'Resseguier $n .1$ ') were subjected to drought stress. Seventy-two glasshouse-grown plants from each genotype were divided into two groups: plants grown under well-watered conditions $180 \%$ of field capacity) and plants grown under water deficit conditions (from 80 to $30 \%$ of field capacity). The whole drought experiment lasted 10 days, during which leaf physiological measurements were performed on fully expanded leaves coming from at least six plants for each genotype and considered time point. Leaf transpiration rate $\left(E, \mathrm{mmol} \mathrm{H}_{2} \mathrm{O} \mathrm{m}^{-2} \mathrm{~s}^{-1}\right)$ measurement was performed in the following experimental conditions: $600 \mu \mathrm{mol}$ of photons $\mathrm{m}^{-2} \mathrm{~s}^{-1}, \mathrm{a} \mathrm{CO}_{2}$ concentration of $380 \mu \mathrm{mol} \mathrm{mol}^{-1}, 1.5 \mathrm{kPa}$ of vapor pressure deficit (VPD) and a block temperature of $25^{\circ} \mathrm{C}$.

As for the mRNA-seq experiment, M4 and 101.14 plants were divided into two replicates (at least six plants for each group) and leaf and roots were sampled at four time points (from T1 to T4 corresponding to 2, 4, 7and 10 Days After Stress Imposition, DASI, respectively). Total RNA was extracted from frozen grapevine tissues of all samples using the "SpectrumTM Plant total RNA Kit" (Sigma) according to manufacturer instructions. All samples were subjected to mRNA-sequencing (mRNA-seq) according to the CRIBI protocol (http://genomics.cribi.unipd.it/main/services/).

DEseq R package (http://www.r-project.org/) was used to perform the statistical analyses for discovering differentially expressed genes (DEGs) by using a multi-factorial approach (Maza et al., 2013). DEGs results from the multifactorial analysis (in particular those in common between all three components and only those in common between $\mathrm{R}$ and T) were grouped based on ontological categories using Blast2GO software v2.5.0 (Götz et al., 2008).

Subsequently, genes belonging to selected categories of GO was carried out "Differential Cluster Analysis" (DCA). Briefly, the DCA consists in i) clusterization, on the basis of expression profiles, of the genes-set related to M4 rootstock; ii) set-up of the corresponding cluster in 101.14; iii) calculation of the correlation values between M4 and 101.14 genes belonging to the same ontological categories; iv) identification of conserved clusters (high correlation) and not (low correlation value) between the two rootstocks.

\section{RESULTS AND DISCUSSION}

The study aims to shed light on the genetic determinism underlying tolerance/ susceptibility to water stress of M4 and 101.14 grapevine rootstocks, displaying high and low levels of tolerance, respectively.

The transpiration rate $(E)$ measured in WW conditions was $2.73 \pm 0.3$ and $2.4 \pm 0.2$ $\mathrm{mmol} \mathrm{H}_{2} \mathrm{O} \mathrm{m}^{-2} \mathrm{~s}^{-1}$ for $\mathrm{M} 4$ and 101.14 genotypes, respectively, and maintained similar values throughout the experiment. On the other hand, under WS, as drought gradually led to severe stress conditions (around 30\% of field capacity), 101.14 plants showed almost complete stomatal closure, whereas M4 plants maintained a transpiration rate of approximately $20 \%$ with respect to the control (Figure 1). These data are in accordance with those discussed by Meggio et al. (2014) that observed a concurrent decrease of net assimilation rate $\left(A_{n}\right)$ and stomatal conductance $\left(\mathrm{g}_{\mathrm{s}}\right)$ in both genotypes at early stages of WS, but at later time points the two genotypes showed a contrasting physiological response to water stress. Indeed, an 
almost complete inhibition of both assimilation and transpiration rates was observed in 101.14, while M4 plants maintained a gs value corresponding to $20 \%$ of that in the control; this allowed higher transpiration rates $(24 \%)$ and therefore $A_{n}$ values maintaining an active plant growth (60\% of that in control plants). These data indicate that, after a decrease of all physiological parameters occurring in both genotypes at the early stages of drought (Meggio et al., 2014), only the M4 genotype was able to maintain higher $E$ and $A_{n}$ rates in more severe stress condition, demonstrating a much better ability to acclimatize than the susceptible genotype.

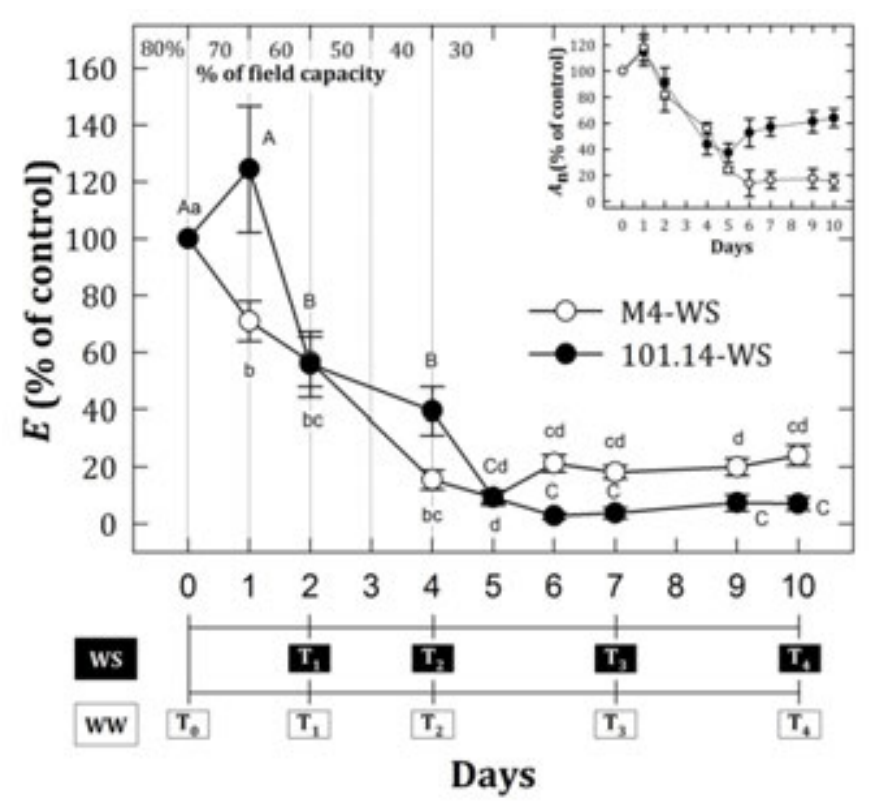

Figure 1. Average $\pm \mathrm{SE}$ values of net $\mathrm{CO}_{2}$ assimilation $(\mathrm{An})$ and leaf transpiration $(E)$ for water stress plants. Results are expressed as a percentage of control. T1-4 represent sampling time points throughout the experimental period after control (T0). Values indicated with the same letters do not significantly differ according to Duncan's test $(\mathrm{P}<0.01)$.

The comparison of leaf and root mRNA-seq data obtained by multifactorial analyses (Figure 2) indicated that in roots the "treatment" factor is the main variable that affected genes expression (7905 DEGs), whereas in leaves the weight of the genotype (i.e., rootstock) was the most prominent (3794 DEGs). This observation is not surprising, given that the root system is the first organ to perceive water deprivation and actively respond to this stress, and thus the type of treatment represents the main variable influencing gene expression. The opposite is true in the leaves, where the genotype factor appears to have a major effect when compared to the other components. This is in agreement with a previous report (Frensch, 1997) that in maize plants undergoing water deprivation, roots and leaves use different strategies to respond to stress with a preferential growth of root system over shoots.

In order to identify specific metabolic pathways differentially affected by drought stress in M4 and 101.14 roots and leaves, the DEGs captured by multifactorial analysis, i.e., the DEGs common to R, T, and P components and those common to rootstocks and treatment components, were associated to their respective GO terms. These represented 4072 and 1152 genes in roots and leaves, respectively. GO terms were grouped into macro-categories. Amongst the macro-categories related to root, "transcription factors" was the one counting the highest number of DEGs, with 307 genes corresponding to 7.5\% of all DEGs considered (4072 in total). There were 209 and 223 "secondary metabolism" and "sugars" DEGs, respectively, corresponding to 5.1 and $5.5 \%$ of total DEGs. The DEGs identified in WS leaves 
highlighted a different weight of ontology categories compared to the root tissue. Transcripts related to "sugars" were the most highly represented, with 73 DEGs (6.3\%). "Transcription factors" and "secondary metabolism" categories were represented with 56 $(4.9 \%)$ and $54(4.7 \%)$ genes, respectively. Finally, 'plant hormones', 'antioxidant responses' and 'cell wall' categories were less represented in both roots and leaves.

Water stress Root

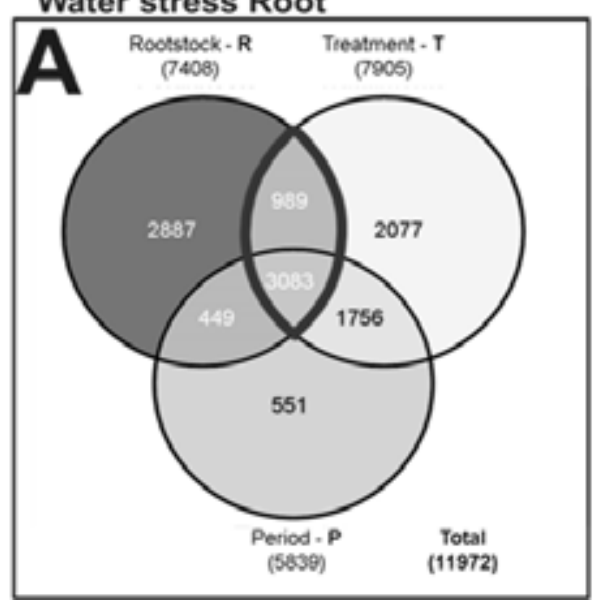

Water stress Leaf

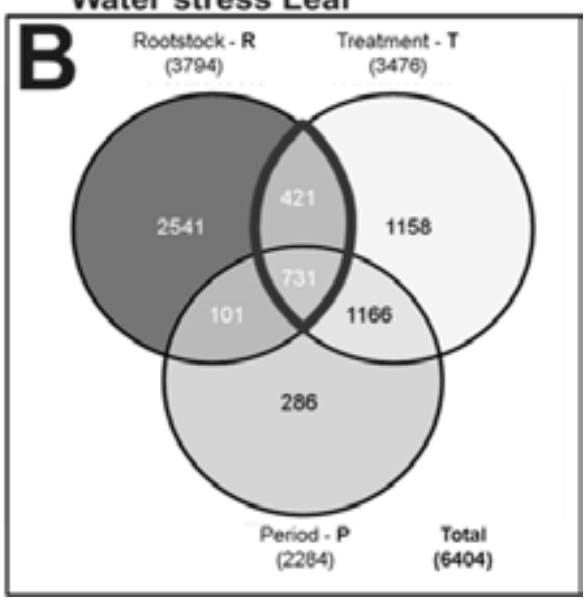

Figure 2. Venn diagrams of DEGs resulting from multifactorial analyses conducted on root and leaf tissues under WS treatment, according to a $\mathrm{p}<0.05$. Number of DEGs influenced by each component are given in brackets; total number of genes influenced by root and leaf tissues are also given ("Total:").

'Secondary metabolism' ontology category was the most interesting because it is common to both root and leaves, but involved different responses (Figure 3). In particular M4 roots (Figure 3A) showed a strong up-regulation of genes involved in resveratrol biosynthesis (e.g., VvSTS18/24/27) after T2 and an induction of four GST-related genes at T1 and T2-T4, in comparison to what observed for 101.14. In addition to the well-known effect of many biotic and abiotic stresses on the induction of STS genes (Versari et al., 2001; Vannozzi et al., 2012), it has recently been reported that oxidative stresses also appear to upregulate STS genes in Vitis rotundifolia hairy roots (Nopo-Olazabal et al., 2014). Differently from what observed for roots, in M4 stressed leaves, transcripts coding for enzymes involved in flavonoids biosynthesis (e.g., CHS, F3H, FLS, LDOX) undergo strong induction at T1 and a strong accumulation at T2 (log2 WS/WW of 2-4) (Figure 3B). The up-regulation of these genes and the accumulation of polyphenols in response to drought in the aerial part of the plant were reported in grapevine and in other species (Castellarin et al., 2007; Ramakrishna and Ravishankar, 2011).

Stilbenes and flavonoids have ROS scavenging activity that protects against oxidative damage and controls ROS levels, which is mandatory for plant survival in the presence of abiotic stresses (Brunetti et al., 2013). Stilbenoids (resveratrol in particular) are powerful defence antioxidant molecules found in several species and their accumulation is particularly high in grapevine (Vannozzi et al., 2012; Höll et al., 2013; Stuart and Robb, 2013). Furthermore, it has been suggested that flavonoids, whose biosynthetic genes are induced only in M4 leaves under WS (Figure 3B), act as antioxidants in plant response to oxidative stresses (Brunetti et al., 2013). Indeed, they protect against oxidative stress due to an excess of excitation energy in the chloroplast by absorbing solar wavelengths (Agati et al., 2012) and environmental perturbations (Agati et al., 2012; Brunetti et al., 2013). Flavonoids may also reduce the activity of 'primary' ROS scavenger enzymes (i.e., SOD and CAT) in the chloroplast (Brunetti et al., 2013). In addition, flavonoids are capable of quenching $\mathrm{H}_{2} \mathrm{O}_{2}$ and other free-radicals, thus protecting the chloroplast membrane from oxidative damage by stabilizing membranes containing non-bilayer lipids (Agati et al., 2012). 

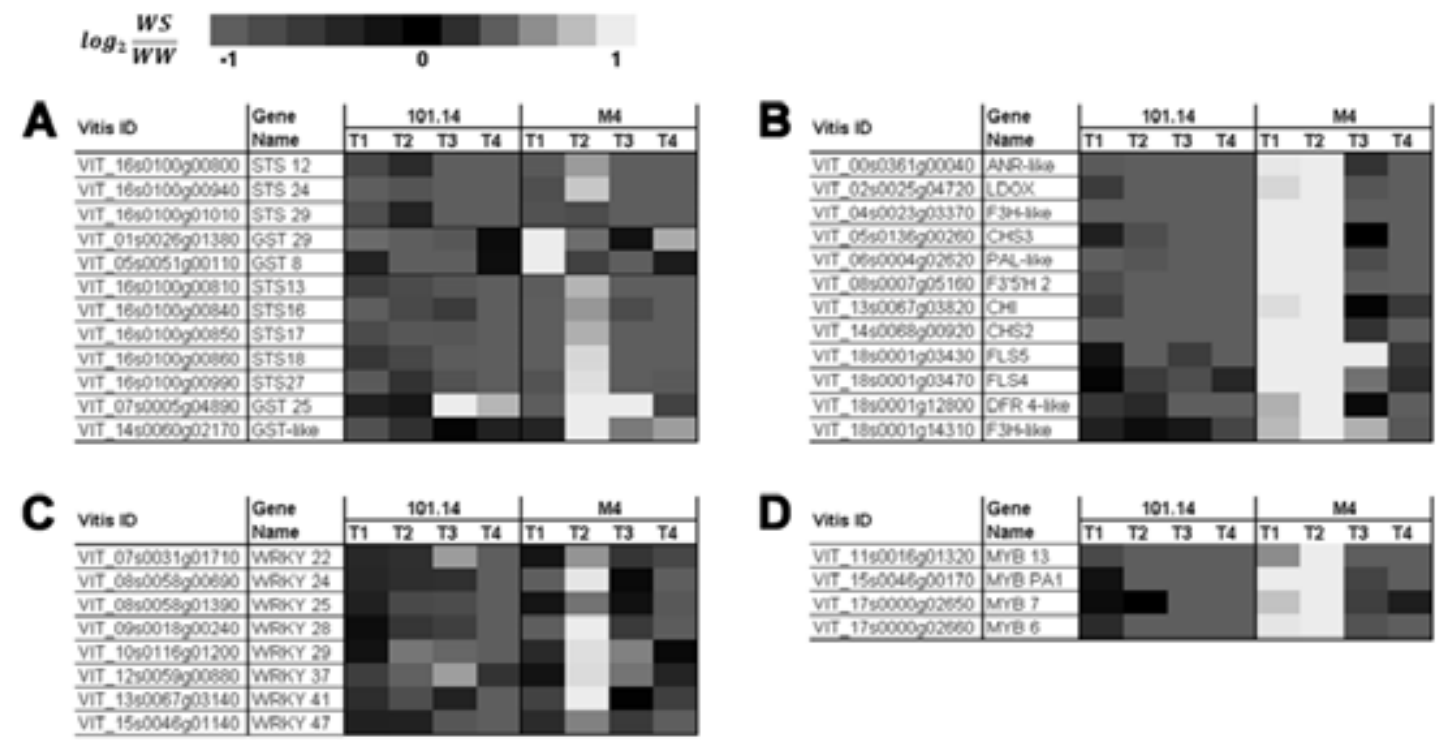

Figure 3. Heat map showing the expression of 101.14 and M4 genes involved in roots (A, C) and leaves (B, D) secondary metabolites biosynthesis (A, B) and transcription factors $(C, D)$. Yellow (value $=1$ ) and blue (value $=-1$ ) indicate up- and downregulated genes upon water stress ( $\log _{2}$ WS/WW mRNAseq counts), respectively. V1 12X identifier (Vitis ID) and gene name are also indicated in the figure.

The data support the hypothesis that in addition to the activation of "primary mechanisms" of ROS scavenging, drought-tolerant Vitis species, such as M4, also induce "secondary mechanisms" leading to the biosynthesis of other types of secondary compounds in roots and leaves.

TFs likely play an important role in the differential regulation of flavonoids/ stilbenoids-related genes in roots and leaves of both M4 and 101.14 genotypes. Stressresponsive TFs interact with cis-elements in the promoter regions of several stress-related genes and thus modulate the expression of target genes resulting in imparting abiotic stress tolerance (Agarwal and Jha, 2010). In root, three classes of TFs (WRKY, MYB and NAC) showed major differences in transcript abundance between M4 and 101.14 in response to water deficit. The most represented among these are WRKY genes (Figure 3C) encoding an important class of transcriptional regulators involved in biotic and abiotic stresses (e.g., drought, high salinity, UV). A relatively large group of $V v W R K Y$ genes were strongly induced in M4 root at 4 DASI. The co-expression of a large number of WRKYs (VvWRKY24/28/29) 37/41) and VvSTSs genes (Figure 3A, C), raises the hypothesis that some of these WRKYs are actively involved in the regulation of STSs gene expression in Vitis species. This relationship is further supported by the presence of W-BOX Cis-regulatory elements in the promoter region of M4 and 101.14 VvSTSs (data not shown). It was shown recently that is possible to predict the expression level of a given gene based on a cis-regulatory network obtained from promoter sequences and gene co-expression networks (Gao et al., 2013). In this context, the higher expression of VvSTSs genes under WS in M4, can be related to the significantly higher frequency of WBOXs in their promoter regions in comparison to that observed in 101.14 and PN40024 (data not shown).

Fewer TFs-related DEGs were observed in leaf compared to root tissues, and most of these TFs belong to the MYB-family. In this study, all MYBs identified as DEGs were induced at $\mathrm{T} 1$ and $\mathrm{T} 2$ (Figure 3D) in the tolerant rootstock and their expression paralleled that observed for DEGs coding for flavonoid biosynthetic enzymes (Figure 3B). A strong connection between MYB and flavonoids is well documented (for a review see Czemmel et al., 2012). R2R3-MYB proteins have been identified as key determinants in regulatory networks controlling the expression of flavonoids-related genes during plant/fruit 
development and in responses to biotic and abiotic stresses.

\section{CONCLUSIONS}

The data provide a comprehensive description of the transcriptomic responses to drought in roots and leaves of two genotypes. In contrast to other studies (Cramer et al., 2007; Tillett et al., 2011), we did not consider responses to water stress that are common to susceptible and tolerant plants (e.g., genes involved in ABA metabolism or those responsible for ROS production and primary ROS scavenging), but rather focused on genes whose expression is strictly related to the tolerant genotype. From this point of view, the data suggest that M4 drought tolerance could be associated to enhanced scavenging capacity of secondary ROS. In water-stressed M4 plants, the higher ROS detoxification ability could allow lateral root growth to be maintained that results in higher water uptake capacity from the soil, as observed by Tsukagoshi (2012). Likewise, at the leaf level a higher $E$ and $A_{n}$, in the drought tolerant genotype would promote active plant growth and photosynthesis. On the contrary, in 101.14 where the oxidative stress is not efficiently counteracted, the functionality of roots and leaves is strongly impaired. The genes and mechanisms found in this study to be the main factors underlying the better adaptation to water stress of the M4 genotype will be further validated using an association genetics approach. The expression of selected candidate genes is currently under evaluation on a large range of genotypes exhibiting differential responses to water stress in order to assess whether the drought tolerance strategies operating in M4 rootstock are conserved in other genotypes and, if so, to use the identified genes as functional markers for the selection of WS-tolerant grapevine rootstocks.

\section{ACKNOWLEDGEMENTS}

This article is dedicated to the memory of our friend and colleague Angelo Ramina, we miss his constructive criticisms and suggestions. This study was supported by the Progetto AGER “SERRES”, grant n² 2010-2105.

\section{Literature cited}

Agarwal, P.K., and Jha, B. (2010). Transcription factors in plants and ABA dependent and independent abiotic stress signalling. Biol. Plant. 54 (2), 201-212 http://dx.doi.org/10.1007/s10535-010-0038-7.

Agati, G., Azzarello, E., Pollastri, S., and Tattini, M. (2012). Flavonoids as antioxidants in plants: location and functional significance. Plant Sci. 196, 67-76 http://dx.doi.org/10.1016/j.plantsci.2012.07.014. PubMed

Brunetti, C., Di Ferdinando, M., Fini, A., Pollastri, S., and Tattini, M. (2013). Flavonoids as antioxidants and developmental regulators: relative significance in plants and humans. Int J Mol Sci 14 (2), 3540-3555 http://dx.doi.org/10.3390/ijms14023540. PubMed

Castellarin, S.D., Matthews, M.A., Di Gaspero, G., and Gambetta, G.A. (2007). Water deficits accelerate ripening and induce changes in gene expression regulating flavonoid biosynthesis in grape berries. Planta 227 (1), 101-112 http://dx.doi.org/10.1007/s00425-007-0598-8. PubMed

Chaves, M.M., Zarrouk, O., Francisco, R., Costa, J.M., Santos, T., Regalado, A.P., Rodrigues, M.L., and Lopes, C.M. (2010). Grapevine under deficit irrigation: hints from physiological and molecular data. Ann. Bot. 105 (5), 661676 http://dx.doi.org/10.1093/aob/mcq030. PubMed

Corso, M., and Bonghi, C. (2014). Grapevine rootstock effects on abiotic stress tolerance. Plant Science Today 1 (3), 108-113 http://dx.doi.org/10.14719/pst.2014.1.3.64.

Cramer, G.R., Ergül, A., Grimplet, J., Tillett, R.L., Tattersall, E.A., Bohlman, M.C., Vincent, D., Sonderegger, J., Evans, J., Osborne, C., et al. (2007). Water and salinity stress in grapevines: early and late changes in transcript and metabolite profiles. Funct. Integr. Genomics 7 (2), 111-134 http://dx.doi.org/10.1007/s10142-006-0039-y. PubMed

Czemmel, S., Heppel, S.C., and Bogs, J. (2012). R2R3 MYB transcription factors: key regulators of the flavonoid biosynthetic pathway in grapevine. Protoplasma 249 (S2, Suppl 2), 109-118 http://dx.doi.org/10.1007/s00709012-0380-z. PubMed

Frensch, J. (1997). Primary responses of root and leaf elongation to water deficits in the atmosphere and soil solution. J. Exp. Bot. 48, 985-999. 
Gao, Z., Zhao, R., and Ruan, J. (2013). A genome-wide cis-regulatory element discovery method based on promoter sequences and gene co-expression networks. BMC Genomics 14 (Suppl 1), S4. PubMed

Götz, S., García-Gómez, J.M., Terol, J., Williams, T.D., Nagaraj, S.H., Nueda, M.J., Robles, M., Talón, M., Dopazo, J., and Conesa, A. (2008). High-throughput functional annotation and data mining with the Blast2GO suite. Nucleic Acids Res. 36 (10), 3420-3435 http://dx.doi.org/10.1093/nar/gkn176. PubMed

Höll, J., Vannozzi, A., Czemmel, S., D’Onofrio, C., Walker, A.R., Rausch, T., Lucchin, M., Boss, P.K., Dry, I.B., and Bogs, J. (2013). The R2R3-MYB transcription factors MYB14 and MYB15 regulate stilbene biosynthesis in Vitis vinifera. Plant Cell 25 (10), 4135-4149 http://dx.doi.org/10.1105/tpc.113.117127. PubMed

Maza, E., Frasse, P., Senin, P., Bouzayen, M., and Zouine, M. (2013). Comparison of normalization methods for differential gene expression analysis in RNA-Seq experiments: a matter of relative size of studied transcriptomes. Commun Integr Biol 6 (6), e25849 http://dx.doi.org/10.4161/cib.25849. PubMed

Meggio, F., Prinsi, B., Negri, A.S., Di Lorenzo, G.S., Lucchini, G., Pitocco, P., Failla, O., Scienza, A., Cocucci, C., and Espen, L. (2014). Biochemical and physiological responses of two grapevine rootstock genotypes to drought and salt treatments. Aust. J. Grape Wine Res. 20 (2), 310-323 http://dx.doi.org/10.1111/ajgw.12071.

Nopo-Olazabal, C., Condori, J., Nopo-Olazabal, L., and Medina-Bolivar, F. (2014). Differential induction of antioxidant stilbenoids in hairy roots of Vitis rotundifolia treated with methyl jasmonate and hydrogen peroxide. Plant Physiol. Biochem. 74, 50-69 http://dx.doi.org/10.1016/j.plaphy.2013.10.035. PubMed

Ramakrishna, A., and Ravishankar, G.A. (2011). Influence of abiotic stress signals on secondary metabolites in plants. Plant Signal Behav 6 (11), 1720-1731 http://dx.doi.org/10.4161/psb.6.11.17613. PubMed

Sharp, R.E., and Davies, W.J. (1979). Solute regulation and growth by roots and shoots of water-stressed maize plants. Planta 147 (1), 43-49 http://dx.doi.org/10.1007/BF00384589. PubMed

Stuart, J., and Robb, E. (2013). Resveratrol and its derivatives as phytoalexins. In Bioactive Polyphenols from Wine Grapes (New York, USA: Springer), p.1-8.

Tillett, R.L., Ergül, A., Albion, R.L., Schlauch, K.A., Cramer, G.R., and Cushman, J.C. (2011). Identification of tissuespecific, abiotic stress-responsive gene expression patterns in wine grape (Vitis vinifera L.) based on curation and mining of large-scale EST data sets. BMC Plant Biol. 11 (1), 86 http://dx.doi.org/10.1186/1471-2229-11-86. PubMed

Tsukagoshi, H. (2012). Defective root growth triggered by oxidative stress is controlled through the expression of cell cycle-related genes. Plant Sci. 197, 30-39 http://dx.doi.org/10.1016/j.plantsci.2012.08.011. PubMed

Vannozzi, A., Dry, I.B., Fasoli, M., Zenoni, S., and Lucchin, M. (2012). Genome-wide analysis of the grapevine stilbene synthase multigenic family: genomic organization and expression profiles upon biotic and abiotic stresses. BMC Plant Biol. 12 (1), 130 http://dx.doi.org/10.1186/1471-2229-12-130. PubMed

Versari, A., Parpinello, G.P., Tornielli, G.B., Ferrarini, R., and Giulivo, C. (2001). Stilbene compounds and stilbene synthase expression during ripening, wilting, and UV treatment in grape cv. Corvina. J. Agric. Food Chem. 49 (11), 5531-5536 http://dx.doi.org/10.1021/jf010672o. PubMed 